\title{
TIME RESPONSE STUDY FOR COMMUNICATION IN PRODUCT LIFECYCLE MANAGEMENT
}

\author{
N.Norazlin ${ }^{* 1,2}$, A.Y. Bani Hashim ${ }^{1}$, M.H.F.M.Fauadi ${ }^{1}$, Teruaki Ito ${ }^{2}$ \\ ${ }^{* 1}$ Faculty of Manufacturing Engineering, Universiti Teknikal Malaysia Melaka, Hang Tuah Jaya, \\ 76100 Durian Tunggal, Melaka, Malaysia \\ ${ }^{2}$ Institute of Technology and Science Tokushima University, Minami-Josanjima 2-1, Tokushima- \\ shi, Tokushima, 77-8506, Japan
}

DOI: https://doi.org/10.29121/IJOEST.v1.i1.2017.01

\begin{abstract}
The evolvement of Internet of thing (IoT) is undeniable by making the management process become more ease at lowest cost as possible. Product lifecycle management (PLM) is a best approach to be embedded the IoT for the entire manufacturing processes. Real cases reported for weak PLM implemented like late market entry faced by A380 while Toyota faced cost loses in repair, deals and market share from massive called made which effect on company reputations. In this paper, traceability becomes a factor among man, machine and management in order to make fast respond on the data retrieved. The term traceability is measured based on response time in real time system to track the information in just in time for one-to-one communication through JAVA programming and two different operating systems as an approach. The communication can be occurred in less than 20 seconds within two different machines. The traceability time is a performance measure for just in time data process which the human behavior factor is neglected for this study. The fastest time response have a potential to optimize the manufacturing management, make more efficient and offer the traceability on product/project status beside improve the flexibility, maintainability, reusability as well as extensibility.
\end{abstract}

Keywords: IoT; PLM; Product Lifecycle Management; Traceability.

Cite This Article: N.Norazlin, A.Y. Bani Hashim, M.H.F.M.Fauadi, \& Teruaki Ito. (2017). TIME RESPONSE STUDY FOR COMMUNICATION IN PRODUCT LIFECYCLE MANAGEMENT. International Journal of Engineering Science Technologies, 1(1), 1-12. doi: 10.29121/IJOEST.v1.i1.2017.01

\section{INTRODUCTION}

The evolvement of information technology open wide door for other fields like business, manufacturing, management and etc. to be moved for high efficiency and performance. Two difference definitions of PLM that bring to same goal of manufacturing process. The perfect combination between people, process and data is an integration concept of PLM (Gmelin and Seuring, 2014) was a first definition as shown in Figure 1. According to Kevin (2013) PLM is a process that possess the ability to leverage investment in product development process by delivering more innovative and impactful products where it is extend from idea generation until product retirement. The initial idea of PLM is to emphasize the customer relationship management where delivering the customer service well is a main factor that most business to compete each other. 


\subsection{Manufacturing in The Future}

Online customization and purchasing is a new disruptive purchasing model that affected the manufacturing system and chain. This model required an evolution management while the operational levels become a huge challenge (Mourtzis, 2016). Terms of Big Data cannot be denied in Industry 4.0 where the only effective solution to manage and control the complexity and disturbances is by adapting the manufacturing networks (Mourtzis, Doukas, \& Psarommatis, 2015). Behind the manufacturing networks, IoT, data exchange, product life cycle management (PLM), business web, social web, computer hardware and software become the pillars. It is view by Mourtzis, Doukas, \& Psarommatis, (2015) in Figure 2 that incorporates the recent trends in internet technologies that able to give better support to the Industry 4.0.

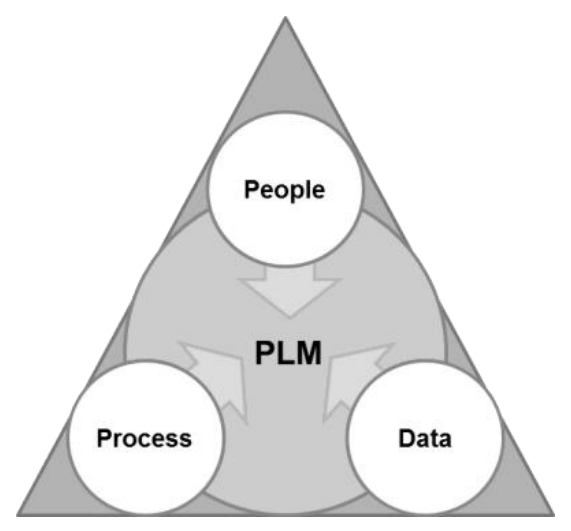

Figure 1: The PLM concept. The perfect combination between people, process and data is an integration concept of PLM (Gmelin and Seuring, 2014). The initial idea of PLM is to emphasize the customer relationship management where delivering the customer service well is a main factor that most business to compete each other.

Any manufacturing field that engaged with network involved its organization in manufacturing and assembly to form raw material into finished product (Choi \& Hong, 2002). The complexity in the system is contributed by the variety that exists in an industry. Complexity is a re-emerged activities that done repeatedly and inspired the methodology of big-data management in computer network to take on complex system. Furthermore it's also energized many research fields with sufficiently fast ability to tackle any problem in many industries (Barabási, 2011). In PLM perfective, a PLM network engaged with entire entities in manufacturing in order to make sure the product produce meet the demand and target. Furthermore the PLM network is aim to ease the manufacturing management by providing the data on-board as well as can be accessed anywhere at any time.

The applications of IoT have compelling the enterprise operations to keep up and meet the market demand. The force of global market makes many industries to rethink their productivity, quality strategies techniques and approach of overall operations management. Industry 4.0 as future manufacturing is targeting to compel the principles and strategies of just in time (JIT), total quality management (TQM), computer integrated manufacturing (CIM), agile manufacturing, lean production, quick respond manufacturing (QRM) as well as supply chain management (SCM) (Gunasekaran, \& Ngai, 2012). 


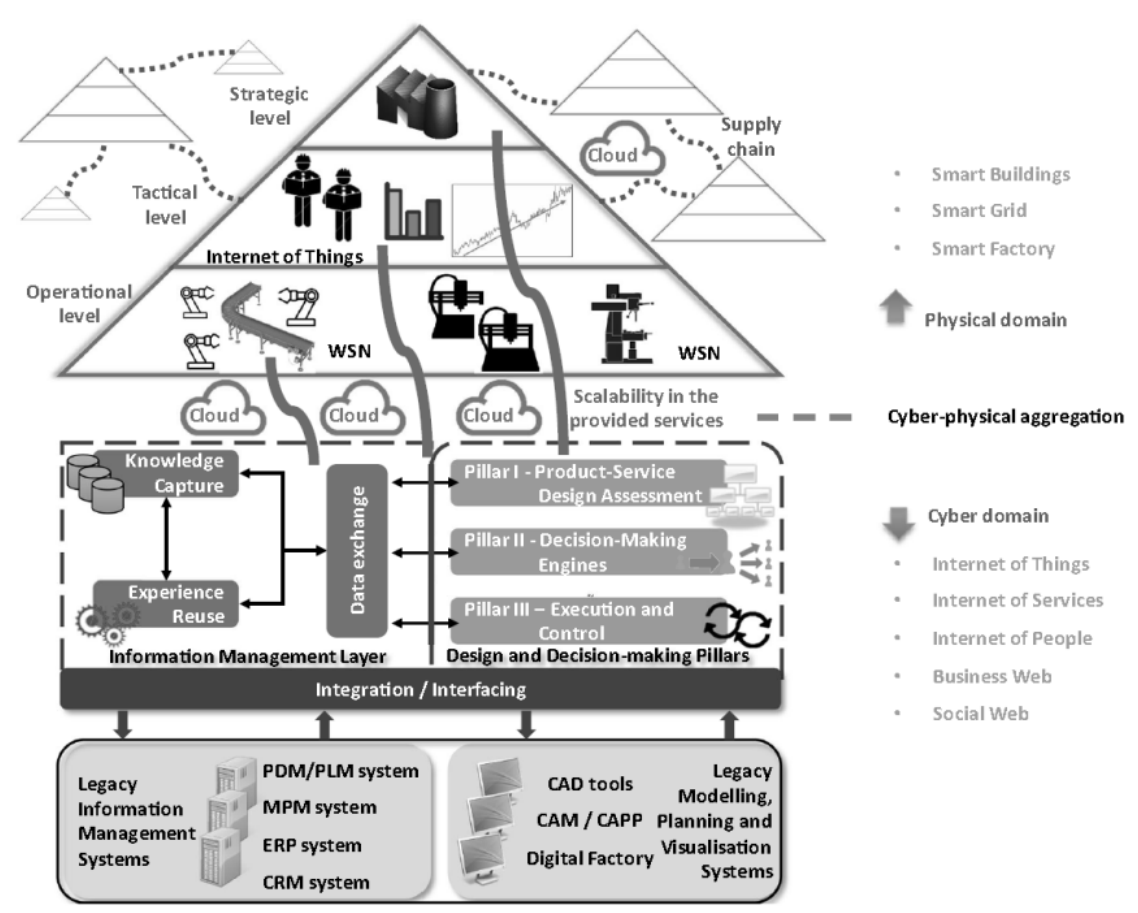

Figure 2: Manufacturing view in the future (Mourtzis, Doukas, \& Psarommatis, 2015). As an emerging manufacturing, the automation is not only automate the physical processes but data also include. The automated of physical processes and information processing able to achieve a

long term sustainable production. The automation processes become a goal in deterministic manufacturing and one of the criteria for Industry 4.0.

The challenge and manufacturing issues in Industry 4.0 is summarized in Figure 3 below where it's divided into three main factors which are man, machine and management. To handle the complexity in manufacturing network, the future focused leadership and mind set is required. Furthermore the more intelligent equipment or machines occupied, the higher skill worker required to operate that. Traceability become a main focused in this study where the usage of IoT is manipulating to track the product information and material used during manufacturing process. The traceability makes the whole manufacturing processes become visible and easy to manage.

PREC-IN monitoring system provides the most effective adjustment in process parameter and its lead to reduce the final product performance. Furthermore, the corrective action is achieved in just-in-time (Boorla, \& Howard, 2016). Smart technologies for manufacturing bring a bundle of complexity in order to manage and control the information either giver or share and improve the communications in near-real-time. The expanding accessibility of 'huge information' has raised the desire that we could make the world more unsurprising and controllable. Indeed, the real time respond (RTT) in communication and management able to overwhelm the instabilities get from delayed response or worst information handling (Helbing, 2013). Industry 4.0 possess the smart technology equipment such as communication devices and information tools in order to inform the customer/client about product status by loading the data in near-real-time or just in time. Beside that the operators accountability and line performance can be evaluated can be informed in near-real-time (Siano, 2014). However, does the devices and tools able to respond in near- 
real-time? In this study, RTT is study by using two different operating system where the signal parsing through socket connection.

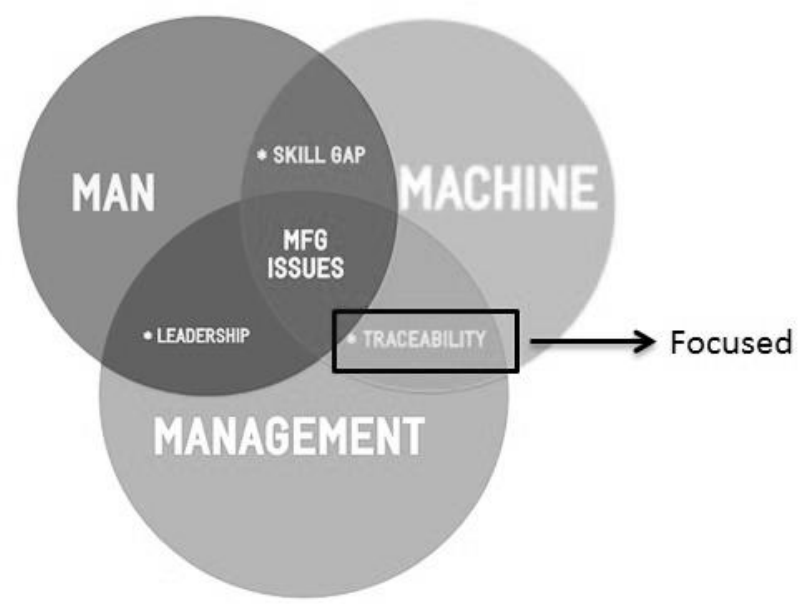

Figure 3: Current manufacturing issues faced. The challenge and manufacturing issues in Industry 4.0 is divided into three main factors which are man, machine and management. To handle the complexity in manufacturing network, the future focused leadership and mind set is required.

\subsection{Issues in PLM}

PLM emphasized the combination of people, process and data to be successfully implemented. However the implementation of PLM also contributes to several losses based on real case scenarios occurred around the world when it's neglected several factors. Figure 4 shows the six issues that been identified from the current study and the factors affected in sustainable PLM.

Green focused should provide an important competitive advantage instead of minimizing the environmental harm only. In to integrate environmental issues into new product development (NPD), the environmental factors must be considered in all stages of the manufacturing process (Polonsky \& Ottman, 1998). The emerging of green technology involve two sides in manufacturing perspective, customers demand and supply from manufacturers which pressuring and responding to it. This point of view enforced the pre-production stage to consider the environmental issues in the design process (Baumann et al., 2002). Polonsky \& Ottman, (1998) believes that the successful of green NPD involve a wide set of stakeholders while Lee \& Kim, (2011) agreed that the suppliers plays a major role for NPD where it's begin from the design concept stage to the prototype development stage. Collaboration and communication are two main factors for green NPD. Collaboration is defined as coordination and alignment with project teams since the green NPD having a broad demand and various inputs and multifunctional product development, to meet market and environmental regulatory requirements become a main reason why the team needs to be coordinated. Effective communication between stakeholders is needed in order to provide information to produce green NPD. The information become extremely valuable in preproduction stage where its involve design and testing in order to ensure the NPD is meet the environmental regulations. 


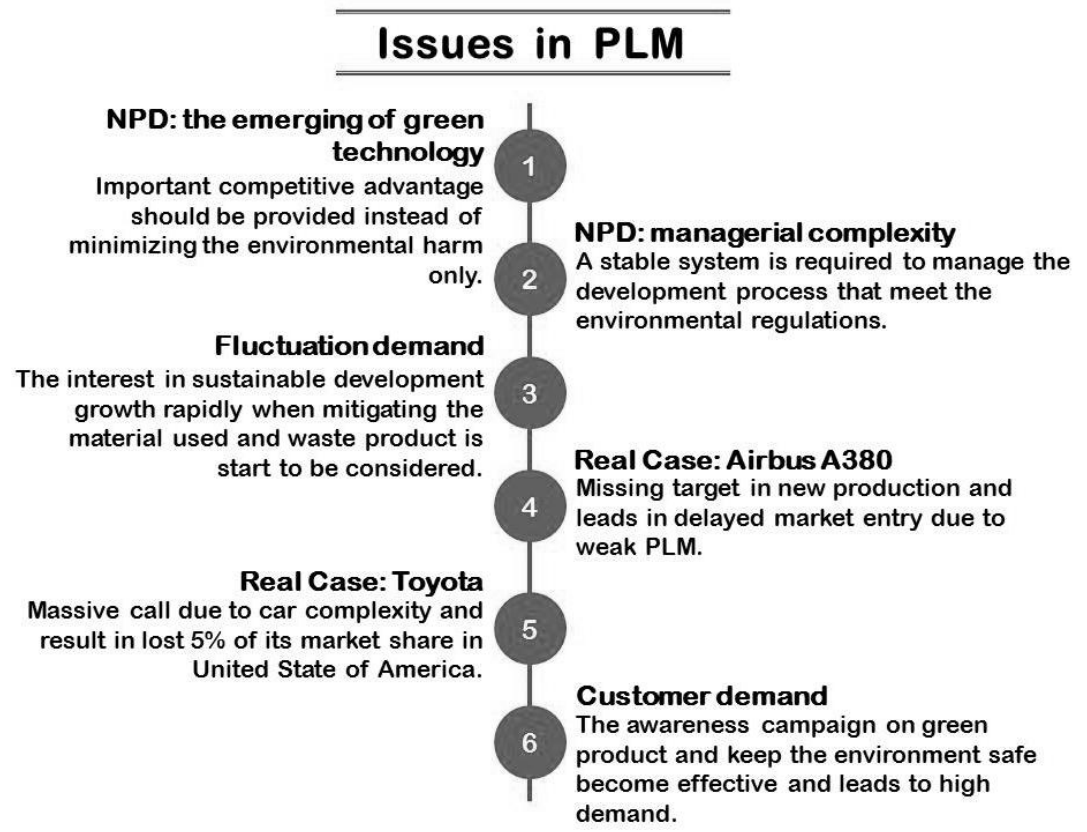

Figure 4: Issues in PLM. In PLM, there are three important factors that make it complete and works efficiently. People, process and data required good collaboration and by intervening the technology into PLM make it become more successful to merge the business globally.

Complexity in NPD required a stable system to manage the development process. To manage the entire PLM is not an easy activity in order to meet the target such as customer demand, early market entry, new invention product and etc. The transforming of virtual production (designing, testing and simulation) into physical production is difficult to control during phase of life. The managerial complexity of PLM becomes cross-enterprise issues and even more challenging. Late market entry and exceed the targeted cost are the serious consequences faced if the company loses control in PLM (Stark, 2015). It is proven by real cases reported when weak PLM was implemented.

i) Case 1: Airbus Company: A380 was reported on missing target in new production and leads to delayed market entry due to their weak product life cycle management (PLM) (TechDrummer, 2008)

ii) Case 2: Toyota Company: Until year 2009, Toyota made a massive vehicles call due to car complexity of 11 major models and over 9 million vehicles. The recalls cost at least $\$ 2$ billion in cost of repair and lost deals. The recall result in lost $5 \%$ of its market share in United State of America and further drops foreseen (Gu, 2010).

The fluctuation demand occurred when the awareness campaign on green product and keep the environment safe become effective. This point enforced company to create new product that comply with environment regulation. The interest in sustainable development growth rapidly when company start to consider mitigating the material used and waste product and any future weakness as well as inefficiencies can be avoided (Bevilacqua et al., 2007). Organizing and managing the sustainable development and NPD become more complex and it's dependent on organized process and technology as a critical success factors (Gmeling \& Seruing, 2014; 
Johnson et al., 2010). PLM required technology as an integrative approach in order to manage the data and process for NPD towards sustainable and efficiently possible in new product process but not in development/design phase only (Gmeling \& Seuring, 2014).

Current practise of PLM is reviewed in Table 1 where the most application is neglected the technology invention in order to manage the data and process. The successful collaboration process can be achieved when PLM able to interact with coordination, information exchange, negotiation and solving conflicts (Wiesner et al., 2015). In PLM, there are three important factors that make it complete and works efficiently. People, process and data required good collaboration and by intervening the technology into PLM make it become more successful to merge the business globally. To reduce the communication barrier cause by geographically factor and the used of web-based management seem the only way to make it successfully manage.

Gaps analysis as shown in Figure 5 has been concluded from the reviews on current PLM implementation and agent web-based application. Too focused on NPD is noticed as the first gap where current implementation or research put a lot of focused in pre-production stage in order to make sure the product development comply with the environment rules and regulations. Second gap reveal the poor information interaction and lack of data exploitation for the entire PLM and Gmeling \& Seruing, (2014) noticed that the sustainable NPD is only feasible to be done in preproduction only and hard to be implemented in the entire of PLM. It is because the company lack of communication by ignoring the information exchange between supplier, customer and retailer become the third gap in current PLM practise. This point of view proved the idea proposed by Polonsky \& Ottman, (1998) where the sustainable NPD should be involved with wide stakeholders. In order to achieve the sustainable PLM, the information exchange and trading is required in entire PLM. By emphasizing the MAS in PLM, it's able to make the idea of sustainable PLM happen with its ability to solve the complexity and expedite the process and secure communication network in management and production process.

Table 1: Studies reviewed on PLM. In PLM, there are three important factors that make it complete and works efficiently. People, process and data required good collaboration and by intervening the technology into PLM make it become more successful to merge the business globally.

\begin{tabular}{|c|c|c|c|}
\hline Author & Issues Focused & $\begin{array}{l}\text { Industrial } \\
\text { Focused }\end{array}$ & Idea Proposed \\
\hline Tao et al., (2016). & 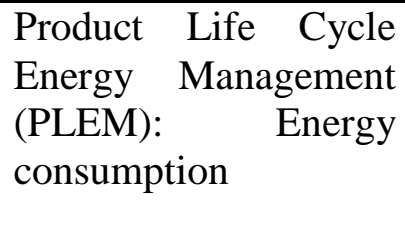 & $\begin{array}{l}\text { Manufacturing } \\
\text { Firms Area: } \\
\text { design, } \\
\text { production and } \\
\text { serve process }\end{array}$ & IoT in PLEM \\
\hline $\begin{array}{l}\text { Wiesner et al., } \\
(\mathbf{2 0 1 5}) \text {. }\end{array}$ & $\begin{array}{l}\text { The interactions } \\
\text { between } \\
\text { (Service Life Cycle } \\
\text { Management) and } \\
\text { PLM (Product Life } \\
\text { Cycle Management) }\end{array}$ & $\begin{array}{l}\text { Manufacturing } \\
\text { Firms }\end{array}$ & $\begin{array}{l}\text { Combining the PLM with } \\
\text { SLM by using the IT } \\
\text { technology. }\end{array}$ \\
\hline
\end{tabular}




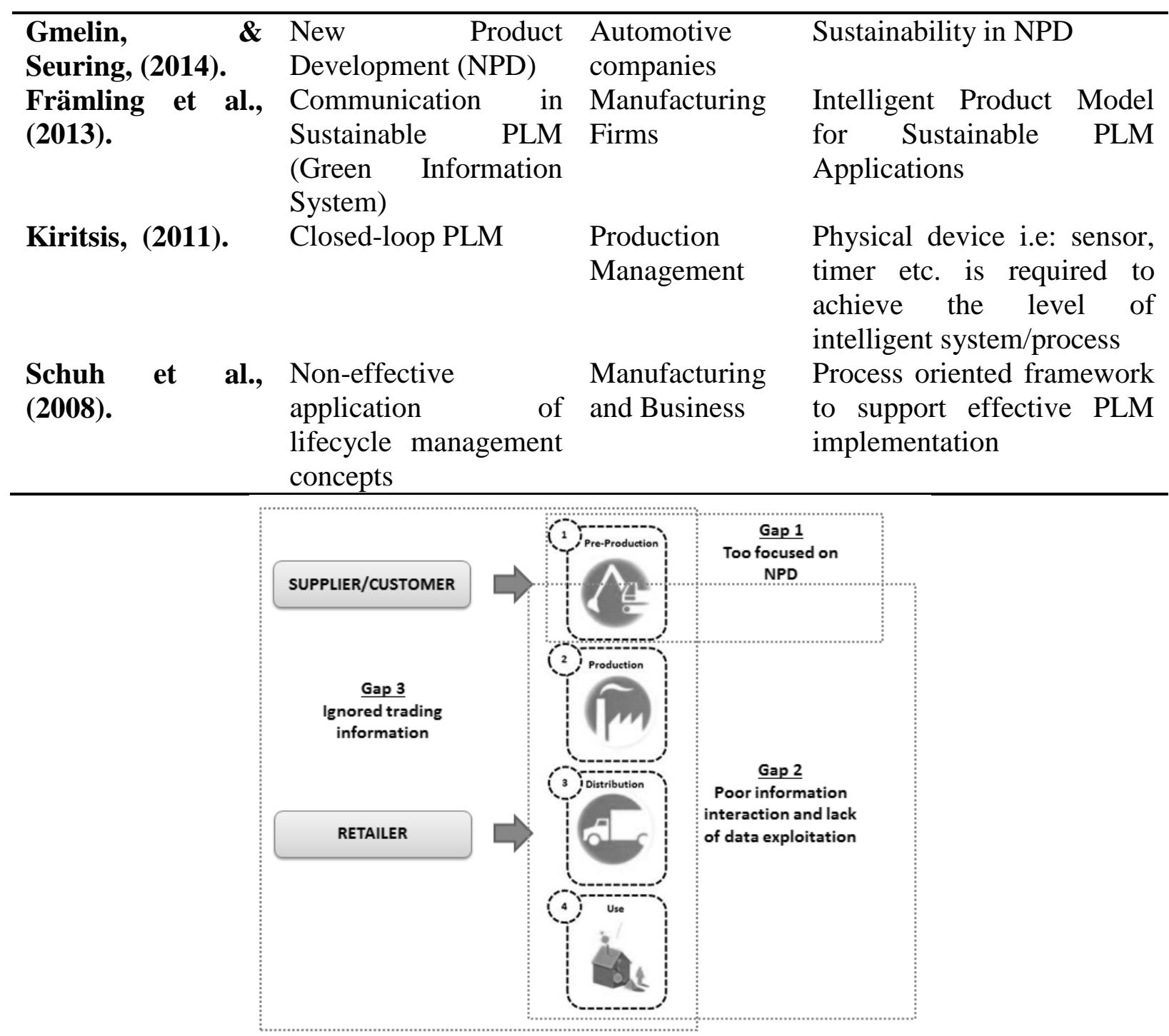

Figure 5 Gaps in current PLM practise. Current practise of PLM neglected the technology invention in order to manage the data and process. The successful collaboration process can be achieved when PLM able to interact with coordination, information exchange, negotiation and solving conflicts.

\section{ROUND TRIP TIME}

Most of the manufacturing target emphasized the time period for every activities including communication. The purpose of the experiments in this section is to verify the optimal cost through RTT. RTT is measure by using socket communication between two or more computer involve client and server environment. The PC or workstation is referring to client which provides with friendly interface such as Windows. While a group of users is provide by server to client for sharing the server program (Xue et. al, 2009).

There are two type of operating system used that running over the network where the details of machines (computers) used is shown in Table 2. Windows and Linux as an operating system provide the communication link between users and the devices (Perchat et. al, 2013). The 
communication between two programs running through socket that constitutes a client-server application. The connection process started with client send a request to the server on specific port. The server is on ready mode for listening and accepts the request from the client. Once the connection is accepted, the client able to use the socket to communicate with the server and begin with read/write from their sockets. The process cycle is shown in Figure 6 below where the activities is keep on happening until the server is disconnected.

From the test conducted, the time is estimated based on the formula (1) below where the $T_{0}$ is a time for server to accept the connection while $T_{1}$ is an ended time for the communication process. The client started to read and write or vice versa during the communication process. From formula (2), the raw mean time is measured in order to know the mode of distribution for the $n$ samples where $n$ is total number of tasks conducted.

$$
\begin{gathered}
\text { RTT }_{n}=T_{1}-T_{0} \\
\text { Raw Mean RTT }=\left[\sum_{i=1}^{i=n} R T T\right]^{-n}
\end{gathered}
$$

Table 2: Machine Details. Windows and Linux as an operating system provide the communication link between users and the devices (Perchat et. al, 2013). The communication between two programs running through socket that constitutes a client-server application.

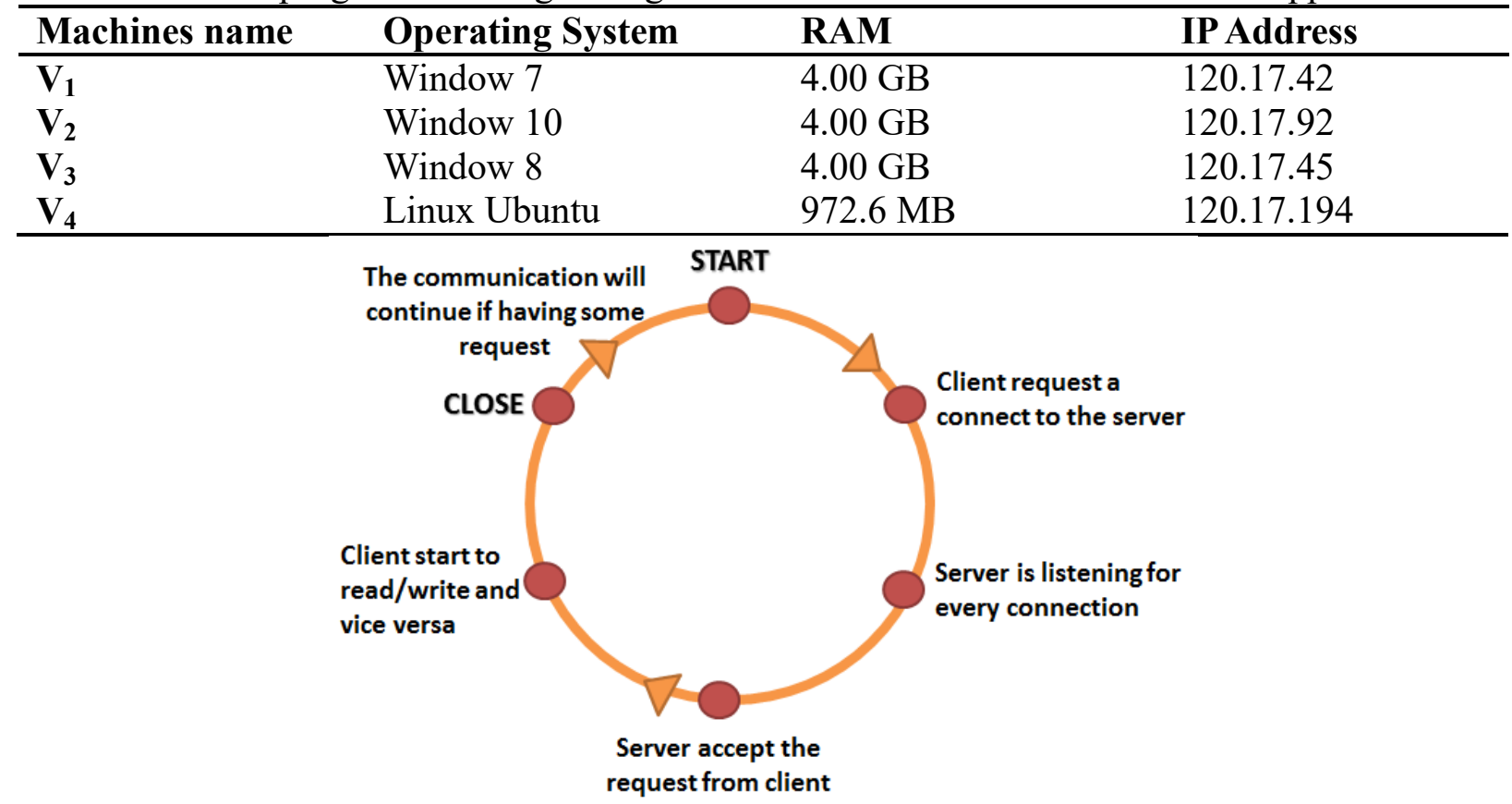

Figure 6: The general process cycle for one way communication through sockets and server. The activities are kept on happening until the server is disconnected. The connection process started with client send a request to the server on specific port. The server is on ready mode for listening and accepts the request from the client. Once the connection is accepted, the client able to use the socket to communicate with the server and begin with read/write from their sockets. 


\section{RESULTS AND DISCUSSIONS}

\subsection{Intra-Platform}

Intra-platform communication occurred as internal signal respond in one machine as shown in Table 3 that obtained from two operating system and four different machines. Huge difference of respond obtained by $\mathrm{V}_{3}$ compare to $\mathrm{V}_{1}, \mathrm{~V}_{2}$ and $\mathrm{V}_{4}$. The different probably cause by the machine itself where $\mathrm{V}_{3}$ is habitualized with programming development compare to others. Furthermore the other machine is rarely used. However, the speed of network also contributes to the long period taken for every machine to respond.

\subsection{Inter-Platform}

For the inter-platform signal responds shown in Table 4, the RTT involved difference server for every testing. Overall performance showed that the server V3 gives the fastest signal respond in $14 \mathrm{~ms}$ compared to others. However, the V4 shown the overall signal respond in $588 \mathrm{~ms}$ where the Linux is an operating system for that machine. Linux give a lot of benefit for computer and network development but it less to be used for manufacturing purpose. For server V1 and server V2 in shown the instability occurred with overall signal respond is $644 \mathrm{~ms}$ and $645 \mathrm{~ms}$ respectively.

Table 3: Intra-platforms' round trip time results. The testing is done for internal operating system communication. The V3 obtained the fastest result compare to others due to high frequency of used for programming.

\begin{tabular}{lllll}
\hline No. of & Machines Name & & & \\
Attempt & $\mathbf{V}_{\mathbf{1}}$ & $\mathbf{V}_{\mathbf{2}}$ & $\mathbf{V}_{\mathbf{3}}$ & $\mathbf{V}_{\mathbf{4}}$ \\
\hline $\mathbf{1}$ & 749 & 847 & 11 & 613 \\
$\mathbf{2}$ & 655 & 842 & 6 & 617 \\
$\mathbf{3}$ & 717 & 874 & 7 & 648 \\
$\mathbf{4}$ & 702 & 893 & 7 & 625 \\
$\mathbf{5}$ & 765 & 825 & 7 & 657 \\
$\mathbf{6}$ & 717 & 1092 & 6 & 638 \\
$\mathbf{7}$ & 733 & 825 & 6 & 655 \\
\hline Mean of & 719.71 & 885.43 & 7.143 & 636.143 \\
RTT (ms) & & & & \\
\hline Raw of & 102.816 & 126.490 & 1.020 & 90.878 \\
Mean on & & & \\
RTT & & & & \\
\hline
\end{tabular}


Table 4: Inter-platforms' round trip time results. The result obtained when the V1, V2, V3, and V4 become a server and communicate with others machine. The respond time is calculated and still showing the V3 is fastest than others.

\begin{tabular}{|c|c|c|c|c|c|c|c|c|c|c|c|c|}
\hline \multirow{3}{*}{ 它 } & \multicolumn{12}{|c|}{ Machines Name } \\
\hline & \multicolumn{3}{|c|}{$V_{1}$} & \multicolumn{3}{|l|}{$V_{2}$} & \multicolumn{3}{|l|}{$\mathbf{V}_{3}$} & \multicolumn{3}{|l|}{$\mathrm{V}_{4}$} \\
\hline & $\mathbf{V}_{2}$ & $\mathbf{V}_{3}$ & $\mathbf{V}_{4}$ & $\mathbf{V}_{1}$ & $\mathbf{V}_{3}$ & $\mathbf{V}_{4}$ & $\mathbf{V}_{1}$ & $\mathbf{V}_{2}$ & $\mathbf{V}_{4}$ & $\mathbf{V}_{1}$ & $\mathbf{V}_{2}$ & $\mathbf{V}_{3}$ \\
\hline 1 & 624 & 702 & 656 & 640 & 719 & 641 & 16 & 15 & 13 & 587 & 592 & 597 \\
\hline 2 & 655 & 639 & 624 & 656 & 641 & 640 & 16 & 13 & 6 & 588 & 588 & 586 \\
\hline 3 & 640 & 639 & 655 & 625 & 656 & 1438 & 14 & 15 & 5 & 589 & 586 & 587 \\
\hline 4 & 671 & 639 & 640 & 641 & 641 & 641 & 16 & 19 & 15 & 588 & 586 & 587 \\
\hline 5 & 640 & 640 & 640 & 641 & 640 & 656 & 20 & 15 & 15 & 590 & 586 & 587 \\
\hline 6 & 639 & 655 & 624 & 672 & 625 & 641 & 19 & 15 & 12 & 586 & 590 & 592 \\
\hline 7 & 640 & 639 & 639 & 640 & 640 & 641 & 14 & 6 & 16 & 592 & 586 & 587 \\
\hline 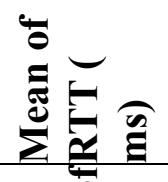 & 644 & 650 & 640 & 645 & 651 & 756 & 16 & 14 & 11 & 589 & 587 & 589 \\
\hline 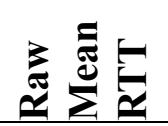 & 92 & 92.86 & 91.43 & 92.14 & 93 & 108 & 2.29 & 2 & 1.57 & 84.17 & 83.86 & 84.14 \\
\hline
\end{tabular}

\section{CONCLUSIONS \& RECOMMENDATIONS}

The fastest respond is obtained by $\mathrm{V}_{3}$ compared to $\mathrm{V}_{1}$ and $\mathrm{V}_{2}$ that used same operating system which is Window. Linux as an operating system for $\mathrm{V}_{4}$ also give better respond even the machine does not frequently used for programming development. Stable communication showed by most of the machine is contributed by stable networking signal and computer performance itself. Linux as an operating system offered the stability in system security compared to others operating system but because of the complexity of system to be used as well as operated become an occupied barrier. Windows as an operating system is typically used in industry while Linux been avoided to be used event the operating system is much better compare to others. Habitualized with programming activities become a contribution factor for $V_{3}$ machine with Windows operating system.

The time response for the communication system possible to be gained in less than 20 seconds and afterwards it depends on how the man or human act on the information given. The three common factors in industry are man, machine and management is strongly related to PLM, traceability and time respond. If the machine shows the effective value, but yet human behaviour does not be able to respond well on the data, so that the management need to play a role in order to make sure the data retrieved is delivered well. In Industry 4.0, the rapid respond is needed for every issue by help from IoT. The fastest respond gained, the more efficient of manufacturing processes is achieve by avoiding the delay in traceability and expedite the contingency plan to be implemented in order to meet the market demand. 


\section{ACKNOWLEDGEMENTS}

The author would like to acknowledge the High Education ministry of Malaysia for the study sponsored and Universiti Teknikal Malaysia Melaka (UTeM) for the facilities support.

\section{REFERENCES}

[1] Barabási, A. L. (2011). The network takeover. Nature Physics, 8(1), 14.

[2] Baumann, H., Boons, F., \& Bragd, A. (2002). Mapping the green product development field: engineering, policy and business perspectives. Journal of Cleaner Production, 10(5), 409-425.

[3] Bevilacqua, M., Ciarapica, F. E., \& Giacchetta, G. (2007). Development of a sustainable product lifecycle in manufacturing firms: a case study. International Journal of Production Research, 45(18-19), 4073-4098.

[4] Boorla, S. M., \& Howard, T. J. (2016). Production monitoring system for understanding product robustness. Advances in Production Engineering \& Management, 11(3), 159.

[5] Choi, T. Y., \& Hong, Y. (2002). Unveiling the structure of supply networks: case studies in Honda, Acura, and DaimlerChrysler. Journal of Operations Management, 20(5), 469-493.

[6] Främling, K., Holmström, J., Loukkola, J., Nyman, J., \& Kaustell, A. (2013). Sustainable PLM through intelligent products. Engineering Applications of Artificial Intelligence, 26(2), 789-799.

[7] Gmelin, H., \& Seuring, S. (2014). Achieving sustainable new product development by integrating product life-cycle management capabilities. International Journal of Production Economics, 154, 166-177.

[8] Gu, X. X. G. (2010). Toyota recalls: revealing the value of secure supply chain (Doctoral dissertation, Massachusetts Institute of Technology).

[9] Gunasekaran, A., \& Ngai, E. W. (2012). The future of operations management: an outlook and analysis. International Journal of Production Economics, 135(2), 687-701.

[10] Helbing, D. (2013). Globally networked risks and how to respond. Nature, 497(7447), 51-59.

[11] Jay Polonsky, M., \& Ottman, J. (1998). Stakeholders' contribution to the green new product development process. Journal of Marketing Management, 14(6), 533-557.

[12] Johnson, M.E., Cochran, J.J., Cox, L.A., Keskinocak, P., Kharoufeh, J.P., Smith, J.C., 2010. Product/Service Design Collaboration: Managing the Product Life Cycle. Wiley Encyclopedia of Operations Research and Management Science. John Wiley \& Sons, Inc.

[13] Kevin Prendeville. (2013). Product Lifecycle Management: The Billion Dollar Lever. Accenture Product Lifecycle Services, Global and North America.

[14] Kiritsis, D. (2011). Closed-loop PLM for intelligent products in the era of the Internet of things. Computer-Aided Design, 43(5), 479-501.

[15] Lee, K. H., \& Kim, J. W. (2011). Integrating suppliers into green product innovation development: an empirical case study in the semiconductor industry. Business Strategy and the Environment, 20(8), 527-538.

[16] Mourtzis, D. (2016). Challenges and future perspectives for the life cycle of manufacturing networks in the mass customisation era. Logistics Research, 9(1), 1-20.

[17] Mourtzis, D., Doukas, M., \& Psarommatis, F. (2015). A toolbox for the design, planning and operation of manufacturing networks in a mass customisation environment. Journal of Manufacturing Systems, 36, 274-286.

[18] Perchat, J., Desertot, M., \& Lecomte, S. (2013). Component based framework to create mobile cross-platform applications. Procedia Computer Science, 19, 1004-1011.

[19] Schuh, G., Rozenfeld, H., Assmus, D., \& Zancul, E. (2008). Process oriented framework to support PLM implementation. Computers in industry, 59(2), 210-218.

[20] Siano, P. (2014). Demand response and smart grids-A survey. Renewable and Sustainable Energy Reviews, 30, 461-478. 
[21] Stark, J. (2015). Product lifecycle management (pp. 1-29). Springer International Publishing.

[22] Tao, F., Wang, Y., Zuo, Y., Yang, H., \& Zhang, M. (2016). Internet of Things in product lifecycle energy management. Journal of Industrial Information Integration, 1, $26-39$.

[23] Tech Drummer, 2008. Case Study: IBM \& Airbus: Tech Drummer.

[24] Wiesner, S., Freitag, M., Westphal, I., \& Thoben, K. D. (2015). Interactions between service and product lifecycle management. Procedia CIRP, 30, 36-41.

[25] Xue, Ming, and Changjun Zhu. The socket programming and software design for communication based on client/server. Circuits, Communications and Systems, 2009. PACCS'09. Pacific-Asia Conference on. IEEE, 2009.

\footnotetext{
*Corresponding author.

E-mail address: norazlin999@gmail.com
} 